Marquette University

e-Publications@Marquette

College of Nursing Faculty Research and

Publications

Nursing, College of

$12-2009$

\title{
Effects on Resilience of Women Family Caregivers of Adults With Serious Mental Illness: The Role of Positive Cognitions
}

Jaclene A. Zauszniewski

Case Western Reserve University

Abir K. Bekhet

Marquette University, abir.bekhet@marquette.edu

M. Jane Suresky

Case Western Reserve University

Follow this and additional works at: https://epublications.marquette.edu/nursing_fac

Part of the Nursing Commons

\section{Recommended Citation}

Zauszniewski, Jaclene A.; Bekhet, Abir K.; and Suresky, M. Jane, "Effects on Resilience of Women Family Caregivers of Adults With Serious Mental Illness: The Role of Positive Cognitions" (2009). College of Nursing Faculty Research and Publications. 326.

https://epublications.marquette.edu/nursing_fac/326 


\section{Marquette University}

\section{e-Publications@Marquette}

\section{Nursing Faculty Research and Publications/College of Nursing}

This paper is NOT THE PUBLISHED VERSION; but the author's final, peer-reviewed manuscript. The published version may be accessed by following the link in the citation below.

Archives of Psychiatric Nursing, Vol. 23, No. 6 (December 2009): 412-422. DOI. This article is (C) Elsevier and permission has been granted for this version to appear in e-Publications@Marquette. Elsevier does not grant permission for this article to be further copied/distributed or hosted elsewhere without the express permission from Elsevier.

\section{Effects on Resilience of Women Family Caregivers of Adults with Serious Mental Illness: The Role of Positive Cognitions}

Jaclene A. Zauszniewski

Frances Payne Bolton School of Nursing, Case Western Reserve University, Cleveland, $\mathrm{OH}$ Abir K. Bekhet

Psychiatric and Mental Health Nursing, Marquette University College of Nursing, Milwaukee, WI M. Jane Suresky

Psychiatric and Mental Health Nursing, Frances Payne Bolton School of Nursing, Case Western Reserve University, Cleveland, $\mathrm{OH}$

This study examined the effects of risk and protective factors on resilience in 60 women family members of adults with serious mental illness. Both the risk factors constituting caregiver burden (strain, stigma, client dependence, and family disruption) and protective factors, including eight positive cognitions were found to predict two indicators of resilience: resourcefulness and sense of coherence. The effects of caregiver burden on resourcefulness and sense of coherence were mediated 
by positive cognitions, lending support to resilience theory and suggesting the need to develop interventions to encourage positive thinking among women caregivers of adults with mental illness.

IN THE UNITED States, more than one in four adults are diagnosed as having mental illness each year (Kessler, Chiu, Demler, \& Walters, 2005). In the most recent U.S. Census, nearly 60 million adults were reported to have a mental disorder (U.S. Census Bureau, 2008). Six percent of these adults had a serious mental illness, one which is severe and disabling (Kessler et al., 2005). The following conditions are classified as serious: major depressive disorder, bipolar disorder, schizophrenia, panic disorder, and other mental disorders that, if left untreated, could lead to severe functional impairment (Bye \& Partridge, 2004).

Among the serious mental disorders, anxiety or mood disorders are most common. About 40 million U.S. adults are diagnosed with an anxiety disorder each year, and 6 million of them have panic disorder (Kessler et al., 2005). Mood disorders, which include major depressive disorder and bipolar disorder, affect approximately 21 million adults, or nearly $10 \%$ of the adult population (Kessler et al., 2005). Major depression affects almost 15 million of U.S. adults or nearly $7 \%$ of the adult population, and bipolar disorder affects almost 6 million U.S. adults or 3\% of the adult population (Kessler et al., 2005). Fewer adults are diagnosed as having schizophrenia-approximately 2.4 million or about $1 \%$ of the adult population (Kessler et al., 2005). However, some researchers believe that this prevalence estimate may be low (Wu, Shi, Birnbaum, Hudson, \& Kessler, 2006).

In the past, persons with serious mental illnesses were commonly institutionalized, but over time, with the deinstitutionalization movement and advances in the development of medications, more mentally ill adults have moved into the community. Some adults with mental illness have been successful in living independently, but a percentage of them remain in the household with family members, who need to help them to manage their daily activities. Even if the family member with mental illness is not living at home, family members are likely to be involved in their ongoing care and support (Lively, Friedrich, \& Rubenstein, 2004).

Therefore, by choice or by necessity, families have taken on the responsibility of caring for their family member with mental illness (Kohn-Wood \& Wilson, 2005, Wynaden et al., 2006). However, caring for individuals with severe mental illness in the community carries a heavy burden for caregivers-more than the burden of caring for other individuals with disabilities, such as mental retardation (Rudnick, 2004). This is especially true for close family caregivers, who experience a poorer sense of well-being that in turn affects the well-being of the person with mental illness (Jungbauer \& Angermeyer, 2002, Rudnick, 2004), creating a vicious circle and more and more tension and strain for family caregivers.

Studies have shown that much of the burden and stress experienced by family caregivers of persons with mentally illness is associated with the stigma associated with mental illness, which leads to social isolation of families, financial difficulties, occupational restrictions, frustration, anxiety, low selfesteem, helplessness, reduction in leisure activities, negative effects on social relationships, experiences of discrimination and refusal, and worry about the future (Muhlbauer, 2002, Rose et al., 2006, Tsang et al., 2003). 
In addition, families may experience disruptions in their daily routines and activities, depending on how much care or support is needed by the adult family member with mental illness. Female relatives of the persons with mental illness report greater burden than their male counterparts, and their quality of life, particularly their emotional well-being, is worse than that of the general population (Fleischmann \& Klupp, 2004). Biegel, Milligan, Putnam, and Song (1994) used the term overall caregiver burden to reflect the stress experienced by family caregivers of persons with mental illness, including feelings of stigma, strain, family disruption, and the dependency needs of the person with mental illness.

To date, most research on family members of the mentally ill has examined the experiences of family members of persons with schizophrenia (e.g., Saunders, 2003, Saunders \& Byrne, 2002, Teschinsky, 2000, Wuerker, 2000). Only a few studies have examined the experiences of family caregivers of persons with anxiety disorders (Stengler-Wenzke, Trosbach, Dietrich, \& Angermeyer, 2004) or major depression (Ahlstrom, Skarsater, \& Danielson, 2007) and bipolar disorder (Perlick et al., 2007). However, the health and quality of life of family members of adults with serious mental illness can be severely compromised by the psychological distress and burden they experience (Saunders, 2003, Walton-Moss et al., 2005).

Yet, some family caregivers of persons with mental illness have been found to become more resilient over time (Enns et al., 1999, Luthar \& Brown, 2007, Richardson, 2002). Although there are a number of definitions for resilience in caregivers (Gillespie, Chaboyer, \& Wallis, 2007), they all share the characteristic of overcoming adversity not only to survive the day-to-day burden associated with caring for a family member who is mentally ill but also to thrive, that is, to grow into a stronger, yet more flexible, and healthier person (Van Breda, 2001).

According to the resilience theory, an individual's resilience is determined by the interaction of risk and protective factors (Van Breda, 2001). The Surgeon General has noted that risk factors are characteristics or variables that make it more likely that an individual will be at-risk for experiencing a health problem (U.S Department of Health and Human Services, 1999). Risk factors involved in caring for a family member with a mental illness include caregiver strain, feelings of stigma, client dependency, and family disruption; together, these factors can seriously compromise the caregiver's resilience. The Surgeon General defines protective factors as characteristics or variables that can improve an individual's response to stress and result in a positive, adaptive outcome (U.S Department of Health and Human Services, 1999). A protective factor in family caregivers is the ability to think positively when faced with adversity. Both the risk and the protective factors can directly affect a family caregiver's resilience. However, the effects of the risk factors on the caregiver's resilience may be influenced (i.e., minimized) by strong protective factors.

In recent research, a number of strengths, characteristics, qualities, and virtues have been identified as indicators of resilience (Richardson, 2002, Saunders, 2003, Van Breda, 2001), and in studies of family caregivers of persons with mental illness, including dementia caregivers, a number of qualities indicative of resilience have been examined, including psychological well-being (Acton, 2002, BergWeger et al., 2000, Brown, 2007, Gallagher-Thompson \& Coon, 2007, Gitlin, 2001, Pinquart \& Sorensen, 2004), personal control (Atienza et al., 2001, Brown, 2007), coping effectiveness (Doornbos, 2002, Gottlieb \& Rooney, 2004, Gottlieb \& Wolfe, 2002, Iwasaki et al., 2002, Lim \& Ahn, 2003), 
hope/optimism (Bland \& Darlington, 2002, Tusaie \& Patterson, 2006), mastery (Hepburn et al., 2007, Murray-Swank et al., 2006, Rose et al., 2006), self-efficacy (DiBartolo, 2002, Fortinsky et al., 2002, Gilliam \& Steffen, 2006, Kuhn \& Fulton, 2004), and hardiness (DiBartolo, 2002).

Two additional indicators of resilience identified by Van Breda (2001) have been examined in studies of family caregivers of persons with mental illness: sense of coherence (Andren \& Elmstahl, 2005, Andren \& Elmstahl, 2008, Suresky et al., 2008) and resourcefulness (Rosswurm et al., 2002, Wang et al., 2007, Zauszniewski et al., 2008, Zauszniewski et al., 2005). Resourcefulness has been defined as a collection of cognitive-behavioral skills for managing adversity to continue to perform one's daily activities at an optimal level (Rosenbaum, 1990, Zauszniewski, 2006). Sense of coherence has been defined as a global orientation toward life that involves cognitive, behavioral, and motivational elements and is expressed in the belief that the world is comprehensible, manageable, and meaningful (Antonovsky, 1979). According to Van Breda (2001), resourcefulness and sense of coherence can be conceptualized as resilience indicators because they reflect qualities for overcoming adversity and becoming even stronger, more flexible, and healthier. Both resourcefulness and sense of coherence have been examined as indicators of resilience in recently published research (Surtees et al., 2006, Zautra et al., 2008). However, these qualities have not been examined in relation to the effects of risk and protective factors within the context of resilience theory. Therefore, in this study of women family members of adults with serious mental illness, we examined the effects of caregiver burden and positive cognitions on these two indicators of resilience.

We also examined whether the effects of caregiver burden (risk factor) on resourcefulness and sense of coherence were mediated or moderated by the effects of positive cognitions (protective factor). Both mediating and moderating variables serve as intervening variables that may alter the relationship between an independent (predictor) and dependent (outcome) variable (Bennett, 2000). Although mediating variables can explain how or why effects occur between independent and dependent variables, moderating variables can specify which effects will exert influence in the relationship between the independent and dependent variables (Kim, Kaye, \& Wright, 2001). In this study, positive cognitions were examined as potential mediating or moderating variables in the relationship between caregiver burden and indicators of resilience.

The research questions were the following: (a) What are the effects of caregiver burden on resourcefulness and sense of coherence? (b) What are the effects of positive cognitions on resourcefulness and sense of coherence? (c) Are the effects of caregiver burden on resourcefulness influenced by positive cognitions? and (d) Are the effects of caregiver burden on sense of coherence influenced by positive cognitions?

\section{Methods}

\section{Design and Sample}

This secondary analysis used data from a larger study of resourcefulness and quality of life in women caregivers of adults with serious mental illness. The findings from that study have been published elsewhere (Suresky et al., 2008, Zauszniewski et al., 2008, Zauszniewski et al., in press). 
The original study obtained data from 60 women caregivers recruited from northeast Ohio; there were equal numbers of Caucasians and African Americans. The study was approved by the university institutional review board. Study participants voluntarily contacted the research office in response to flyers that were posted throughout the community (see Zauszniewski et al., 2008). The women's ages ranged from 23 to 65 years $(M=46.28 ; S D=11.71)$, and the ages of their family members with mental illness ranged from 18 to $65(M=37.75 ; S D=13.96)$. The family members with mental illness were diagnosed as having schizophrenia (45\%), bipolar disorder (45\%), major depression (8\%), and panic disorder (2\%; Zauszniewski et al., 2008).

\section{Instruments}

Four measures from the original study were used for this secondary analysis: measures of caregiver burden, positive cognitions, sense of coherence, and resourcefulness.

Caregiver burden included variables that reflected the risk factors of caregiver strain, feelings of stigma, client dependence, and family disruption. It was measured by the 27 -item Overall Caregiver Burden Scale (Biegel et al., 1994). Responses on this scale are given on a 5-point Likert Scale ranging from never (0) to always (4). Scores may range from 0 to 108, with higher scores indicating greater overall burden experienced by the caregiver (Biegel et al., 1994). An internal consistency estimate of 0.89 has been reported, and confirmatory factor analysis revealed four factors reflecting the four dimensions (Biegel et al., 1994).

Positive cognitions reflect optimistic thoughts that may function as protective factors. The 8-item Depressive Cognition Scale (DCS; Zauszniewski, 1995) was used to operationalize positive cognitions, as follows. The DCS uses a 6-point Likert scale from strongly agree (5) to strongly disagree (0) to indicate the degree to which a particular statement describes the individual's current thoughts. The items are phrased positively so that strong agreement with an item indicates the presence of a positive cognition. Scores may range from 0 to 40, and higher scores indicate more positive cognitions. The DCS has reported internal consistency estimates of 0.78 and 0.75 in elders and caregivers, respectively (Zauszniewski, 1995, Zauszniewski et al., 2002), and construct validity was established by significant correlations in the expected directions $(P<.001)$ with measures of depression, resourcefulness, adaptive functioning, and life satisfaction $(r=0.54,-0.37,-0.60,-0.57$, respectively; Zauszniewski, 1995). Confirmatory factor analysis indicated the presence of a single factor with all item loadings exceeding $0.30 ; 40 \%$ of the total variance was explained (Zauszniewski, 1997a).

Sense of coherence, an indicator of resilience, was measured by the 13-item Sense of Coherence Scale (SOC-13; Antonovsky, 1993), which uses a 7-point Likert scale from seldom or never (1) to very often or always (7) to measure the frequency of occurrence of an event or situation. Scores may range from 13 to 91, with higher scores, after reversing scores on five items phrased in the negative direction, indicating a greater sense of coherence. Alpha values in 127 studies using SOC-13 ranged from .70 to .92 (Eriksson \& Lindstrom, 2005). Construct validity for this scale has been supported by significant correlations with theoretically related constructs in the expected direction: self-esteem $(r=0.65, P<$ $.001)$, mastery $(r=0.68, P<.001)$, adequacy of attachment $(r=0.37, P<.001)$, and psychopathology $(r$ $=-0.44, P<.001 ;$ Bengtsson-Tops \& Hansson, 2001). 
Resourcefulness, a second resilience indicator, was measured by the 36 -item Self-Control Schedule (SCS;Rosenbaum, 1990), a well known measure of learned resourcefulness. Respondents use a 6-point Likert scale to indicate the degree to which they believe the item describes their behavior, ranging from very much like me (5) to not at all like me (0). Scores may range from 0 to 180; higher composite scores, after reverse scoring for 11 items negatively phrased, indicate greater resourcefulness. Internal consistency estimates ranging from 0.75 to 0.85 have been reported in studies with older adults (Zauszniewski, 1997b, Zauszniewski, 1997c). Construct validity has been demonstrated by significant correlations between the SCS and self-ratings of resourcefulness $(r=0.35)$, psychosocial attributes $(r=$ $0.60)$, depression $(r=-0.30)$, adaptive functioning $(r=0.45)$, and life satisfaction $(r=0.38$;

Zauszniewski, 1997c).

\section{Results}

The study examined the effects of overall caregiver burden, including caregiver strain, feelings of stigma, client dependency, and family disruption (risk factors), on two indicators of resilience, resourcefulness and sense of coherence, and the degree to which positive cognitions (protective factors) mediated or moderated these effects. Preliminary data analyses were run to ensure that the statistical assumptions for multiple regression were not violated. The means, standard deviations, ranges, and reliability estimates for the four major study variables are reported in Table 1; the correlation matrix for all study variables is shown in Table 2.

Table 1. Overall Caregiver Burden, Positive Cognitions, Resourcefulness, and Sense of Coherence of Women Family Caregivers of Adults With Mental Illness $(N=60)$

\begin{tabular}{|l|l|l|l|l|}
\hline Variables & $M( \pm S D)$ & Range & Possible Range & $\alpha$ \\
\hline Caregiver burden & $45.4( \pm 19.96)$ & $10-87$ & $0-108$ & .94 \\
\hline Positive cognitions & $31.6( \pm 6.83)$ & $16-40$ & $0-40$ & .87 \\
\hline Resourcefulness & $113.8( \pm 18.08)$ & $73-157$ & $0-180$ & .81 \\
\hline Sense of coherence & $59.8( \pm 13.90)$ & $27-86$ & $13-91$ & .86 \\
\hline
\end{tabular}

Table 2. Correlations Among Major Study Variables

\begin{tabular}{|l|l|l|l|l|}
\hline & 1. Caregiver Burden & 2. Positive Cognitions & 3. Resourcefulness & 4. Sense of Coherence \\
\hline 1 & - & $-0.404(.001)$ & $-0.378(.003)$ & $-0.328(.010)$ \\
\hline 2 & & - & $0.649(.000)$ & $0.626(.000)$ \\
\hline 3 & & & - & $0.770(.000)$ \\
\hline 4 & & & - \\
\hline
\end{tabular}

Note. Values inside the parentheses are $P$ values.

Four models were tested to determine the mediating or moderating effects of positive cognitions on the relationships between caregiver burden and resourcefulness and between caregiver burden and sense of coherence. The centering technique was used to minimize the multicolinearity between the first-order term (caregiver burden) and the interaction term (positive cognitions; Kim et al., 2001).

\section{Effects of Risk Factors on Resilience}

The effects of the risk factors constituting caregiver burden on sense of coherence and resourcefulness were examined together using simple regression. First, a simple linear regression was calculated to 
predict resourcefulness based on caregiver burden. A significant relationship was found, $F(1,58)=9.69$, $P<.01$, with an $R^{2}=0.143$ and $B=-0.378, P<.01$. That is, lower caregiver burden predicted greater resourcefulness in these women family members of adults with serious mental illness.

Second, simple linear regression was calculated to predict sense of coherence based on caregiver burden. This relationship was also significant, $F(1,58)=7.01, P<.01$, with an $R^{2}=0.108$ and $B=-0.328$, $P<.01$. Lower caregiver burden predicted greater sense of coherence in these women family members of adults with serious mental illness. Thus, both indicators of resilience were significantly predicted by the risk factors constituting overall caregiver burden.

\section{Effects of Protective Factors on Resilience}

The effects of the eight positive cognitions on sense of coherence and resourcefulness were examined together using simple regression. A simple linear regression was calculated to predict resourcefulness based on the eight positive cognitions. A significant relationship was found, $F(1,58)=42.13, P<.001$, with an $R^{2}=0.421$ and $B=0.649, P<.001$. Thus, greater positive cognitions predicted greater resourcefulness in these women family members of adults with serious mental illness.

In the final regression equation, sense of coherence was regressed on the eight positive cognitions. A significant relationship was found, $F(1,58)=84.45, P<.001$, with an $R^{2}=0.593$ and $B=0.770, P<.001$. Again, similar to the findings for resourcefulness, greater positive cognitions predicted greater sense of coherence in these women family members. Thus, both indicators of resilience were significantly predicted by the protective factor of positive cognitions.

\section{Mediation of Effects of Risk Factors on Resilience by Protective Factors}

The first test of mediation involved examination of the effects of positive cognitions on the relationship between overall caregiver burden and resourcefulness. In the simple regression analyses, both caregiver burden and positive cognitions were significantly associated with resourcefulness. Before testing for mediation, positive cognitions were regressed on caregiver burden. A significant relationship was found, $F(1,58)=11.31, P<.001$, with an $R^{2}=0.163$ and $B=-0.404, P<.001$. Thus, lower caregiver burden predicted greater positive cognitions in the women family members of adults with serious mental illness.

Hierarchical regression was used to examine the mediating effects of positive cognitions on the relationship between caregiver burden and resourcefulness (Figure 1). Overall caregiver burden was entered in the first step, and positive cognitions were entered in the second step. The dependent variable in this analysis was resourcefulness. Following Step 1 , the model was significant, $F(1,58)=$ $9.69, P<.01$, and caregiver burden accounted for $14 \%$ of the variance in resourcefulness. When positive cognitions were added in Step 2 , the model remained significant, $F(2,57)=22.12, P<.001$, and the incremental $R^{2}$ was 0.29 . However, there was a substantial drop in the beta weight of caregiver burden, from -.38 to -.14, when positive cognitions entered the equation and caregiver burden was no longer significant in predicting resourcefulness, demonstrating the mediating effects of the positive cognitions. 
Step 1: Caregiver

Burden
$\longrightarrow=-.38(P=.003)$ Resourcefulness

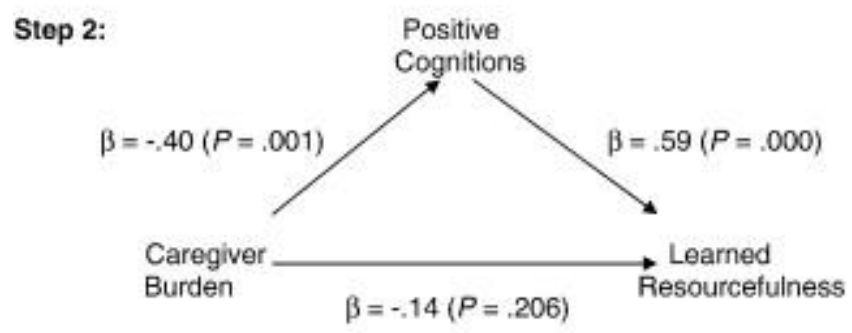

Fig 1. Mediating effects of positive cognitions on the relationship between caregiver burden and resourcefulness.

A second hierarchical regression was performed to examine the mediating effects of positive cognitions on the relationship between caregiver burden and sense of coherence (Figure 2). As in the hierarchical model described above, overall caregiver burden was entered on the first step, and positive cognitions were entered on the second step. The dependent variable was sense of coherence. Following Step 1, the model was significant, $F(1,58)=7.01, P<.01$, and caregiver burden accounted for $11 \%$ of the variance in sense of coherence. When positive cognitions were added in Step 2 , the model remained significant, $F(2,57)=41.56, P<.001$, and the incremental $R^{2}$ was 0.48 . However, there was a substantial drop in the beta weight of caregiver burden, from -.33 to -.02, when positive cognitions entered the equation and caregiver burden was no longer a significant predictor of sense of coherence, demonstrating the mediating effects of the positive cognitions.
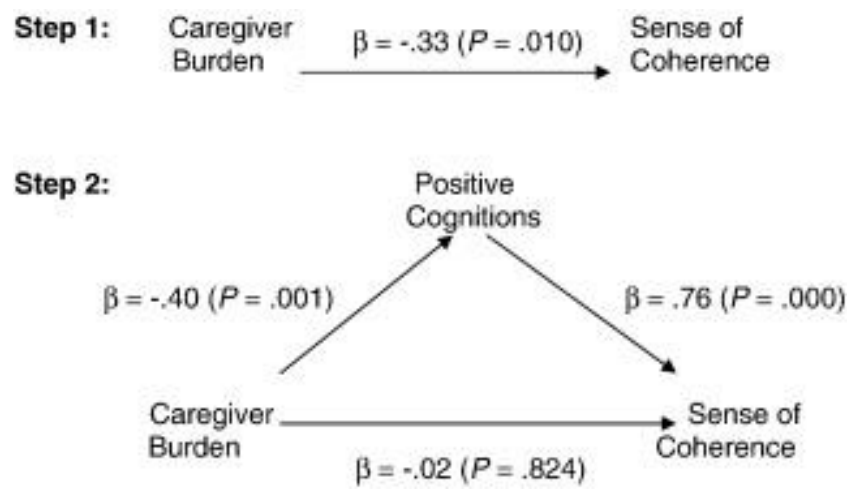

Fig 2. Mediating effects of positive cognitions on the relationship between caregiver burden and sense of coherence.

\section{Moderation of the Effects of Risk Factors on Resilience by Protective Factors}

Parallel analyses were performed to test for the moderating effects of positive cognitions on resourcefulness and sense of coherence. The first test involved examination of the moderating effects of positive cognitions on the relationship between overall caregiver burden and resourcefulness. $A$ three-step hierarchical regression analysis was used in which overall caregiver burden was entered in Step 1, positive cognitions were entered in Step 2, and an interaction term reflecting the centered value of the product of caregiver burden multiplied by positive cognitions was entered in Step 3. Fig 3, Fig 4 display the beta weights for caregiver burden, positive cognitions, and the interaction of these variables in predicting resourcefulness and sense of coherence, respectively. 


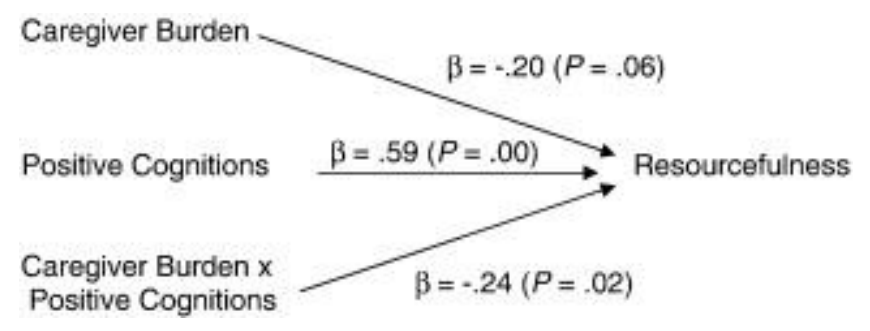

Fig 3. Moderating effects of positive cognitions on resourcefulness.

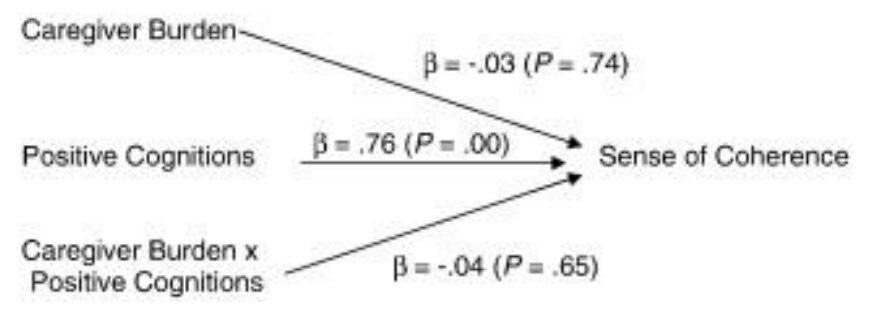

Fig 4. Moderating effects of positive cognitions on sense of coherence.

Hierarchical regression was used to examine the moderating effects of positive cognitions on the relationship between caregiver burden and resourcefulness (Figure 3). Overall caregiver burden was entered in Step 1, positive cognitions in Step 2, and the interaction of Caregiver burden $\times$ Positive cognitions in Step 3. The dependent variable was resourcefulness. Following Step 1, the model was significant, $F(1,58)=9.69, P<.01$, and caregiver burden accounted for $14 \%$ of the variance in resourcefulness. After Step 2, with the addition of positive cognitions, the model remained significant, $F(2,57)=22.12, P<.001$; the incremental $R^{2}$ was 0.29 . At Step 3 , with the addition of the interaction of Caregiver burden $\times$ Positive cognitions, the model remained significant, $F(3,56)=18.06, P<.001$; however, there was an increase of only 0.06 in the incremental $R^{2}$. Upon entry of the interaction term in Step 3, no effect of caregiver burden on resourcefulness was found; however, the effects of positive cognitions on resourcefulness remained significant $(B=0.59, P<.001)$, and the interaction effect was also significant $(B=-0.24, P<.02)$, indicating the presence of partial moderation.

Hierarchical regression was also used to examine the moderating effects of positive cognitions on the relationship between caregiver burden and sense of coherence (Figure 4). As in the analysis reported above, overall caregiver burden was entered in Step 1, positive cognitions in Step 2, and the interaction of Caregiver burden $\times$ Positive cognitions in Step 3. The dependent variable was sense of coherence. Following Step 1, the model was significant, $F(1,58)=7.01, P<.01$, and caregiver burden accounted for $11 \%$ of the variance in sense of coherence. After Step 2, with the addition of positive cognitions, the model remained significant, $F(2,57)=41.56, P<.001$; the incremental $R^{2}$ was 0.48 . At Step 3 , with the addition of the interaction of Caregiver burden $\times$ Positive cognitions, the model remained significant, $F(3,56)=27.39, P<.001$; however, there was an increase of only 0.002 in the incremental $R^{2}$. Upon entry of the interaction term in Step 3, no effect of caregiver burden on sense of coherence was found; however, the effects of positive cognitions on sense of coherence remained highly significant $(B=0.76$, $P<.001)$. An interaction effect was not found, indicating the absence of a moderating effect on sense of coherence by positive cognitions. 


\section{Discussion}

This study represents a first attempt to examine the mediating and moderating effects of positive cognitions on the relationship between caregiver burden and resilience. Although the mediating effect of positive cognitions on resilience have not been previously examined in caregivers, strong associations between similar variables (i.e., positive affect, positive attitudes, and positive appraisal) and resilience have been reported in military medical personnel (Maguen et al., 2008) and college students (Steinhardt \& Dolbier, 2008). In this study, two resilience indictors, resourcefulness and sense of coherence, were examined in women family caregivers of adults with serious mental illness. The effects of the risk factors constituting caregiver burden, including strain, feelings of stigma, client dependence, and family disruption, on these women's resilience were mediated by positive cognitions, which served as protective factors.

\section{Effects on Resourcefulness}

More specifically, our results indicated that positive cognitions had mediating and partially moderating effects on the relationship between caregiver burden and resourcefulness. These findings are consistent with a study of diabetic women by Zauszniewski et al. (2002), which found that positive cognitions mediated the effects of depressive symptoms on resourcefulness. In that study, diabetic women had greater resourcefulness when they used more positive cognitions, which reduced the severity of their depressive symptoms (Zauszniewski et al., 2002).

The findings from this study are also consistent with a study of retired elders conducted by Bekhet, Zauszniewski, and Wykle (2008), in which positive cognitions were found to have a direct effect on resourcefulness. That study also suggested that the effects of relocation to a retirement community on elders' adjustment might be mediated or moderated by positive cognitions (Bekhet et al., 2008).

Finally, this study's findings are consistent with those reported by Zauszniewski et al. (2005), who studied African American women caregivers of elders with dementia. In that study, positive cognitions and daily stress were significant predictors of resourcefulness, although the effects of daily stress on resourcefulness were not mediated by positive cognitions (Zauszniewski et al., 2005).

\section{Effects on Sense of Coherence}

The study also found that positive cognitions had mediating effects on the relationship between caregiver burden and sense of coherence. Although there have been no previous studies of the mediating effects of positive cognitions on sense of coherence, other researchers have reported associations between positive attitudes or positive appraisal of one's situation and sense of coherence in teenagers (Sollerhed, Ejlertsson, \& Apitzsch, 2005) and brain tumor patients and their spouses (Strang \& Strang, 2001). In addition, Suresky et al. (2008) examined the effects of sense of coherence on the relationship between caregiver burden and quality of life in women family members of adults with serious mental illness, but that study did not evaluate the effects of positive cognitions.

There are a number of limitations of the study related to sampling and methodological issues. First, the use of convenience sampling limits the generalizability of the findings because participants in this study may not be representative of all women family caregivers. Second, because the study was crosssectional, it is difficult to assess changes in the study variables over time. Further, Rosenbaum (1990) postulated that learned resourcefulness is acquired throughout life, and thus, measuring 
resourcefulness at a single point may not take into account previous resourcefulness (Bekhet et al., 2008). Similarly, given the cross-sectional design of the study reported here, it is difficult to conclude whether sense of coherence is open to change even after exposure to stressful experiences (Suresky et al., 2008). Future longitudinal studies would be useful in examining causal effects among the study variables in women family caregivers. Finally, given the small sample size, caution must be used in drawing conclusions about the findings.

\section{Conclusion}

The findings provide direction for the development of resilience theory that integrates sense of coherence and resourcefulness as indicators of resilience and highlights protective factors (positive cognitions) and risk factors (burden). Our findings provide direction for developing and testing community-based interventions to strengthen positive thinking and thus help family members of persons with serious mental illness to cope with the stress and burden of caregiving. The study points to a clear need to focus on the family unit when planning care for persons with severe mental illness. In addition, family members of those with mental illness should be encouraged to participate in support groups that provide opportunities to learn from the experiences of others. Enhancement of the resilience of family members of persons with serious mental illness will contribute to both their own well-being and the well-being of those for whom they provide care.

\section{Acknowledgment}

Funding for the study was provided by a Research Initiation Grant (Frances Payne Bolton School of Nursing) awarded to Dr. Jaclene A. Zauszniewski for her study of "Resourcefulness and Quality of Life in Family Members of Adults With Serious Mental Illness."

The authors acknowledge the editorial assistance of Elizabeth M. Tornquist of the University of North Carolina at Chapel Hill.

\section{References}

Acton, 2002. Acton G.J. Health-promoting self-care in family caregivers. Western Journal of Nursing Research, 24 (1) (2002), pp. 73-86

Ahlstrom et al., 2007. Ahlstrom B.H., Skarsater I., Danielson E. Major depression in a family: What happens and how to manage-A case study. Issues in Mental Health Nursing, 28 (2007), pp. 691-706

Andren \& Elmstahl, 2005. Andren S., Elmstahl S. Family caregivers' subjective experiences of satisfaction in dementia care: Aspects of burden, subjective health and sense of coherence. Scandinavian Journal of Caring Science, 19 (2005), pp. 157-168

Andren \& Elmstahl, 2008. Andren S., Elmstahl S. The relationship between caregiver burden, caregivers' perceived health and their sense of coherence in caring for elders with dementia. Journal of Clinical Nursing, 17 (2008), pp. 790-799

Antonovsky, 1979. Antonovsky A. Health, stress, and coping. San Francisco: Jossey-Bass. Antonovsky, A. (1993). The structure and properties of the sense of coherence scale. Social Science and Medicine, 36 (1979), pp. 725-733

Atienza et al., 2001. Atienza A.A., Collins R., King A.C. The mediating effects of situational control on social support and mood following a stressor: A prospective study of dementia caregivers in 
their natural environments. The Journals of Gerontology: Series B: Psychological and social sciences, 56 (3) (2001), pp. 129-140

Bekhet et al., 2008. Bekhet A.K., Zauszniewski J.A., Wykle M.L. Milieu change and relocation adjustment in elders. Western Journal of Nursing Research, 30 (1) (2008), pp. 113-129

Bengtsson-Tops \& Hansson, 2001. Bengtsson-Tops A., Hansson L. The validity of Antonovsky's sense of coherence measure in a sample of schizophrenic patients living in the community. Journal of Advanced Nursing, 33 (4) (2001), pp. 432-438

Bennett, 2000. Bennett J.A. Mediator and moderator variables in nursing research: Conceptual and statistical differences. Research in Nursing and Health, 23 (2000), pp. 415-420

Berg-Weger et al., 2000. Berg-Weger M., Rubio D.M., Tebb S.S. Living with and caring for older family members: Issues related to caregiver well-being. Journal of Gerontological Social Work, 33 (2) (2000), pp. 47-62

Biegel et al., 1994 Biegel D.E., Milligan S.E., Putnam P.L., Song L.Y. Predictors of burden among lower socioeconomic status caregivers of persons with chronic mental illness. Community Mental Health Journal, 30 (5) (1994), pp. 473-494

Bland \& Darlington, 2002. Bland R., Darlington Y. The nature and sources of hope: Perspectives of family caregivers of people with serious mental illness. Perspectives in Psychiatric Care, 38 (2) (2002), pp. 61-68

Brown, 2007. Brown W. Care recipients' psychological well-being: The role of sense of control and caregiver type. Aging and Mental Health, 11 (4) (2007), pp. 405-414

Bye \& Partridge, 2004. Bye L., Partridge J. State level classification of serious mental illness: A case for a more uniform standard. Journal of Health and Social Policy, 19 (2) (2004), pp. 1-29

DiBartolo, 2002. DiBartolo M.C. Exploring self-efficacy and hardiness in spousal caregivers of individuals with dementia. Journal of Gerontological Nursing, 28 (4) (2002), pp. 24-33

Doornbos, 2002. Doornbos M.M. Family caregivers and the mental health care system: Reality and dreams. Archives of Psychiatric Nursing, 16 (1) (2002), pp. 39-46

Enns et al., 1999. Enns R., Reddon J., McDonald L. Indications of resilience among family members of people admitted to a psychiatric facility. Psychiatric Rehabilitation Journal, 23 (2) (1999), pp. 127-133

Eriksson \& Lindstrom, 2005. Eriksson M., Lindstrom B. Validity of Antonovsky's sense of coherence scale: A systematic review. Journal of Epidemiology and Community Health, 59 (6) (2005), pp. 460-466

Fleischman \& Klupp, 2004. Fleischman H., Klupp A. Quality of life in relatives of mentally ill people. Psychiatric Praxis, 31 (1) (2004), pp. S114-S116

Fortinsky et al., 2002. Fortinsky R.H., Kercher K., Burant C.J. Measurement and correlates of family caregiver self-efficacy for managing dementia. Aging and Mental Health, 6 (2) (2002), pp. 153160

Gallagher-Thompson \& Coon, 2007. Gallagher-Thompson D., Coon D.W. Evidence-based psychological treatments for distress in family caregivers of older adults. Psychology and Aging, 22 (1) (2007), pp. 37-51

Gillespie et al., 2007. Gillespie B.M., Chaboyer W., Wallis M. Development of a theoretically derived model of resilience through concept analysis. Contemporary Nurse: A Journal for the Australian Nursing Profession, 25 (1/2) (2007), pp. 124-135

Gilliam \& Steffen, 2006. Gilliam C.M., Steffen A.M. The relationship between caregiving self-efficacy and depressive symptoms in dementia family caregivers. Aging and Mental Health, 10 (2) (2006), pp. 79-86 
Gitlin, 2001. Gitlin L.N. Effectiveness of home environmental interventions for individuals with dementia and family caregivers. Home Health Care Consultant, 8 (9) (2001), pp. 22-26

Gottlieb \& Rooney, 2004. Gottlieb B.H., Rooney J.A. Coping effectiveness: Determinants and relevance to the mental health and affect of family caregivers of persons with dementia. Aging and Mental Health, 8 (4) (2004), pp. 364-373

Gottlieb \& Wolfe, 2002. Gottlieb B.H., Wolfe J. Coping with family caregiving to persons with dementia: A critical review. Aging and Mental Health, 6 (4) (2002), pp. 325-342

Hepburn et al., 2007. Hepburn K., Lewis M., Tomatore J., Sherman C.W., Bremer K.L. The savvy caregiver program: The demonstrated effectiveness of a transportable dementia caregiver psychoeducation program. Journal of Gerontological Nursing, 33 (3) (2007), pp. 30-36

Iwasaki et al., 2002. Iwasaki Y., Ishikawa K., Shimizu K., Miyazaki S. Coping in family caregiving for relatives with mental illness: Family responsiveness and self-nurturing. Journal of Japan Academy of Nursing Science, 22 (4) (2002), pp. 21-32 [Abstract]

Jungbauer \& Angermeyer, 2002. Jungbauer J., Angermeyer M.C. Living with a schizophrenic patient: A comparative study of burden as it affects parents and spouses. Psychiatry, 65 (2002), pp. 110123

Kessler et al., 2005. Kessler R.C., Chiu W.T., Demler O., Walters E.E. Prevalence, severity, \& comorbidity of 12-month DSM-IV Disorders in the National Comorbidity Survey replication. Archives of General Psychiatry, 62 (2005), pp. 617-627

Kim et al., 2001. Kim J.S., Kaye J., Wright L.K. Moderating and mediating effects in causal models. Issues in Mental Health Nursing, 22 (2001), pp. 63-75

Kohn-Wood \& Wilson, 2005. Kohn-Wood L.P., Wilson M.N. The context of caretaking in rural areas: Family factors influencing the level of functioning of seriously mentally ill patients living at home. American Journal of Community Psychology, 36 (1/2) (2005), pp. 1-13

Kuhn \& Fulton, 2004. Kuhn D., Fulton B.R. Efficacy of an educational program for relatives of persons in the early stages of Alzheimer's disease. Journal of Gerontological Social Work, 42 (3/4) (2004), pp. 109-130

Lim \& Ahn, 2003. Lim Y.N., Ahn Y. Burden of family caregivers with schizophrenic patients in Korea. Applied Nursing Research, 16 (2) (2003), pp. 110-117

Lively et al., 2004. Lively S., Friedrich R.M., Rubenstein L. The effect of disturbing illness behaviors on siblings of persons with schizophrenia. Journal of the American Psychiatric Nurses Association, 10 (5) (2004), pp. 222-232

Luthar \& Brown, 2007. Luthar S.S., Brown P.J. Maximizing resilience through diverse levels of inquiry: Prevailing paradigms, possibilities, \& priorities for the future. Development and Psychopathology, 19 (2007), pp. 931-955

Maguen et al., 2008. Maguen S., Turcotte D.M., Peterson A.L., Dremsa T.L., Garb H.N., McNally R.J., Litz B.T. Description of risk and resilience factors among military medical personnel before deployment to Iraq. Military Medicine, 173 (2008), pp. 1-9

Muhlbauer, 2002. Muhlbauer S. Experience of stigma by families with mentally ill members. Journal of the American Psychiatric Nurses Association, 8 (2002), pp. 76-83

Murray-Swank et al., 2006. Murray-Swank A.B., Lucksted A., Medoff D.R., Yang Y., Wohlheiter K., Dixon L.B. Religiosity, psychosocial adjustment, \& subjective burden of persons who care for those with mental illness. Psychiatric Services, 57 (3) (2006), pp. 361-365

Perlick et al., 2007. Perlick D.A., Rosenheck R.A., Miklowitz D.J., Chessick C., Wolff N., Kaczynski R., Ostacher M., Patel J., Desai R. Prevalence and correlates of burden among caregivers of 
patients with bipolar disorder enrolled in the systematic treatment enhancement program for bipolar disorder. Bipolar Disorder, 9 (2007), pp. 262-273

Pinquart \& Sorensen, 2004. Pinquart M., Sorensen S. Associations of caregiver stressors and uplifts with subjective well-being and depressive mood: A meta-analytic comparison. Aging and Mental health, 8 (5) (2004), pp. 438-449

Richardson, 2002. Richardson G.E. The metatheory of resilience and resiliency. Journal of Clinical Psychology, 58 (3) (2002), pp. 307-321

Rose et al., 2006. Rose L.E., Mallinson R.K., Gerson L.D. Mastery, burden, \& areas of concern among family caregivers of mentally ill persons. Archives of Psychiatric Nursing, 20 (1) (2006), pp. 4151

Rosenbaum, 1990. Rosenbaum M. Learned resourcefulness on coping skills, self-control, and adaptive behavior. Springer Publishing Company, New York (1990)

Rosswurm et al., 2002. Rosswurm M.A., Larrabee J.H., Zhang J. Training family caregivers of dependent elderly adults through on-site and telecommunication programs. Journal of Gerontological Nursing, 28 (2002), pp. 27-38

Rudnick, 2004. Rudnick A. Burden of caregivers of mentally ill individuals in Israel: A family participatory study. International Journal of Psychosocial Rehabilitation, 9 (1) (2004), pp. 147152

Saunders, 2003. Saunders J.C. Families living with severe mental illness: A literature review. Issues in Mental Health Nursing, 24 (2) (2003), pp. 175-198

Saunders \& Byrne, 2002. Saunders J.C., Byrne M.M. A thematic analysis of families with schizophrenia. Archives of Psychiatric Nursing, 16 (5) (2002), pp. 217-223

Sollerhed et al., 2005. Sollerhed A.C., Ejlertsson G., Apitzsch E. Predictors of strong sense of coherence and positive attitudes to physical education in adolescents. Scandinavian Journal of Public Health, 33 (2005), pp. 334-342

Steinhardt \& Dolbier, 2008. Steinhardt M., Dolbier C. Evaluation of a resilience intervention to enhance coping strategies and protective factors and decrease symptomatology. Journal of American College Health, 56 (4) (2008), pp. 445-453

Stengler-Wenzke et al., 2004. Stengler-Wenzke K., Trosbach J., Dietrich S., Angermeyer M.C. Experience of stigmatization by relatives of patients with obsessive compulsive disorder. Archives of Psychiatric Nursing, 18 (3) (2004), pp. 88-96

Strang \& Strang, 2001. Strang S., Strang P. Spiritual thoughts, coping, \& sense of coherence in brain tumor patients and their spouses. Palliative Medicine, 15 (2001), pp. 127-134

Suresky et al., 2008. Suresky M.J., Zauszniewski J.A., Bekhet A.K. Sense of coherence and quality of life in women family members of the seriously mentally ill. Issues in Mental Health Nursing, 29 (2008), pp. 265-278

Surtees et al., 2006. Surtees P.G., Wainwright N.W.J., Khaw K.T. Resilience, misfortune, \& mortality: Evidence that sense of coherence is a marker of social stress adaptive capacity. Journal of Psychosomatic Research, 61 (2) (2006), pp. 221-227

Teschinsky, 2000. Teschinsky U. Living with schizophrenia: The family experience. Issues in Mental Health Nursing, 21 (2000), pp. 387-396

Tsang et al., 2003. Tsang H.W., Tam P.K., Chan F., Cheung W.M. Sources of burden on families of individuals with mental illness. International Journal of Rehabilitation Research, 26 (2) (2003), pp. $123-130$ 
Tusaie \& Patterson, 2006. Tusaie K.R., Patterson K. Relationships among trait, situational, \& comparative optimism: Clarifying concepts for a theoretically consistent and evidence-based intervention to maximize resilience. Archives of Psychiatric Nursing, 20 (1) (2006), pp. 144-150

U.S. Census Bureau, 2008. U.S. Census Bureau, U.S. Census Bureau Population Estimates by Demographic Characteristics. Table 2: Annual Estimates of the Population by Selected Age Groups and Sex for the United States: April 1, 2000 to July 1, 2007 (NC-EST2007-02). Population Division, U.S. Census Bureau (2008). Available at: http://www.census.gov/popest/national/asrh/NC-EST2007/NC-EST2007-02.xls. Release Date: May 1, 2008

U.S. Department of Health and Human Services, 1999, U.S. Department of Health and Human Services. Mental Health: A Report of the Surgeon General-Chapter 2: Epidemiology of mental illness. U.S. Department of Health and Human Services, Substance Abuse and Mental Health Services Administration, Center for Mental Health Services, National Institutes of Health, National Institute of Mental Health, Rockville, MD (1999)

Van Breda, 2001. Van Breda A.D. Resilience theory: A literature review. South African Military Health Service, Pretoria, South Africa (2001). Available: http://www.vanbreda.org/adrian/resilience.htm

Walton-Moss et al., 2005. Walton-Moss B., Gerson L., Rose L. Effects of mental illness on family quality of life. Issues in Mental health Nursing, 26 (2005), pp. 627-642

Wang et al., 2007. Wang S., Rong J., Chen C., Wei S., Lin K. A study of stress, learned resourcefulness and caregiver burden among primary caregivers of schizophrenic adolescents. Journal of Nursing (China), 54 (5) (2007), pp. 37-47. [Abstract]

Wu et al., 2006. Wu E.Q., Shi L., Birnbaum H., Hudson T., Kessler R. Annual prevalence of diagnosed schizophrenia in the USA: A claims data analysis approach. Psychological Medicine, 36 (2006), pp. $1535-1540$

Wuerker, 2000. Wuerker A.K. The family and schizophrenia. Issues in Mental Health Nursing, 21 (2000), pp. 127-141

Wynaden et al., 2006. Wynaden D., Ladzinski U., Lapsley J., Landsborough I., Butt J., Hewitt V. The caregiving experience: How much do health professionals understand? Collegian, 13 (3) (2006), pp. 6-10

Zauszniewski, 1995. Zauszniewski J.A. Development and testing of a measure of depressive cognitions in older adults. Journal of Nursing Measurement, 3 (1) (1995), pp. 31-41

Zauszniewski, 1997a. Zauszniewski J.A. The Depressive Cognition Scale: Further psychometric evaluation. Journal of Nursing Measurement, 5 (2) (1997), pp. 191-200

Zauszniewski, 1997b. Zauszniewski J.A. Teaching resourcefulness skills to older adults. Journal of Gerontological Nursing, 23 (2) (1997), pp. 16-20

Zauszniewski, 1997c. Zauszniewski J.A. Evaluation of a measure of learned resourcefulness in older adults. Journal of Nursing Measurement, 5 (1) (1997), pp. 71-86

Zauszniewski, 2006. Zauszniewski J.A. Resourcefulness. J.J. Fitzpatrick, M. Wallace (Eds.), Encyclopedia of nursing research, Spring Publishing Company, New York (2006), pp. 256-258

Zauszniewski et al., 2008. Zauszniewski J.A., Bekhet A.K., Suresky M.J. Factors associated with perceived burden, resourcefulness, \& quality of life in female family members of adults with serious mental illness. Journal of the American Psychiatric Nurses Association, 14 (2) (2008), pp. $125-135$ 
Zauszniewski et al., in press. Zauszniewski, J. A., Bekhet, A. K., \& Suresky, M. J. (in press). Relationships among stress, depressive cognitions, resourcefulness and quality of life in female relatives of seriously mentally ill adults. Issues in Mental Health Nursing.

Zauszniewski et al., 2002. Zauszniewski J.A., McDonald P.E., Krafcik K., Chung C. Acceptance, cognitions, \& resourcefulness in women with diabetes. Western Journal of Nursing Research, 24 (7) (2002), pp. 728-750

Zauszniewski et al., 2005. Zauszniewski J.A., Picot S.J., Roberts B.L., Debanne S.M., Wykle M.L.

Predictors of resourcefulness in African American women. Journal of Aging and Health, 17 (5) (2005), pp. 609-633

Zautra et al., 2008. Zautra A.J., Hall J.S., Murray K.E. Resilience: A new integrative approach to health and mental health research. Health Psychology Review, 2 (1) (2008), pp. 41-64 